\title{
Long-term heat stabilisation by (natural) polyols in heavy metal- and zinc-free poly(vinyl chloride)
}

\author{
Johan Steenwijk $^{\text {a,b }}$, Rik Langerock ${ }^{c}$, Daan S. van Es ${ }^{\text {a }}$, Jacco van Haveren ${ }^{\text {a }}$, \\ John W. Geus ${ }^{\mathrm{b}}$, Leonardus W. Jenneskens ${ }^{\mathrm{b}, *}$ \\ ${ }^{a}$ Agrotechnology \& Food Innovations (A\&F B.V.), Wageningen University and Research Centre, P.O. Box 17, \\ NL-6700 AA Wageningen, The Netherlands \\ ${ }^{\mathrm{b}}$ Debye Institute, Organic Chemistry and Catalysis, Utrecht University, Padualaan 8, NL-3584 CH, Utrecht, The Netherlands \\ ${ }^{\mathrm{c}}$ Limburgse Vinyl Maatschappij NV (LVM), Industriepark Schoonhees, H. Hartlaan 2030, B-3980, Tessenderlo, Belgium
}

Received 21 February 2005; received in revised form 13 April 2005; accepted 28 April 2005

Available online 20 June 2005

\begin{abstract}
The long-term heat stabilisation efficiency of (natural) polyol additives in heavy metal- and zinc-free poly(vinyl chloride) (PVC) has been investigated. It is shown that polyols, such as sorbitol and xylitol, markedly reduce the dehydrochlorination rate and improve Congo Red values. Extraction experiments on unprocessed and ground-processed PVC-sorbitol (1.0 phr) mixtures after thermal degradation at $200{ }^{\circ} \mathrm{C}$ revealed that especially in the ground-processed PVC-sorbitol system, sorbitol is partly converted into its mono- and dianhydro-derivatives 1,4-sorbitan and isosorbide, respectively. Apparently, the $\mathrm{HCl}$ released during thermal degradation acts as the catalyst. Similar intramolecular cyclodehydration reactions also occur with the natural polyols, erythritol and xylitol, under these conditions. Scrutiny of the measured dehydrochlorination rates and the Congo Red values for groundprocessed heavy metal- and zinc-free PVC-polyol mixtures show that in particular polyols containing primary hydroxyl groups exert long-term heat stabilisation and that they act as efficient $\mathrm{HCl}$ scavengers.
\end{abstract}

(c) 2005 Elsevier Ltd. All rights reserved.

Keywords: PVC; Additives; Thermal degradation; Stabilisers; Renewable resources; Sorbitol; 1,4-Sorbitan; Isosorbide; Intramolecular cyclodehydration

\section{Introduction}

In 2000 , ca. $5.8 \times 10^{6}$ ton of poly(vinyl chloride) (PVC) was used in Europe [1]. Notwithstanding due to its intrinsic thermal instability, the application of heat stabilisers (additives) is a prerequisite for PVC processing, i.e. under processing conditions $\mathrm{HCl}$ will be released from the PVC, which ultimately acts as an auto-catalyst leading to severe discolouration and degradation of the polymer. Of the annual European stabiliser consumption

\footnotetext{
* Corresponding author. Tel.: +31 30 2533128; fax: +31 30 2534533.

E-mail address: 1.w.jenneskens@chem.uu.nl (L.W. Jenneskens).
}

(approximately $1.8 \times 10^{5}$ ton) ca. $70 \%$ still consists of lead salts and soaps [2]. Since there is a societal concern with respect to the application of heavy metals, the European PVC industry has made a commitment to phase out the use of lead stabilisers by 2015 [2]. Although alternative stabiliser systems based on tin, calcium/zinc and calcium/organics are already available, they still require further improvement in order to achieve a comparable price/performance. In this context the application of efficient and cost effective long-term co-stabilisers is of interest. For example, the natural polyol, sorbitol, may offer a 'green', environmentally benign solution. Sorbitol is an abundant, food-grade and cost-effective polyol that can be readily handled and 
processed. In fact, sorbitol is already applied as an additive for long-term heat stabilisation in heavy metalstabilised PVC [3,4]. Besides natural polyols synthetic polyols, viz. pentaerythritol, dipentaerythritol and trimethylolpropane (TMP), are also used [5]. However, they suffer from drawbacks like high costs and unsuitable melting points for processing.

Here, we wish to report the results of a systematic investigation on the long-term heat stabilisation of (natural) polyol additives in a heavy metal- and zincfree PVC formulation with varying compositions. The long-term heat stability is assessed using well-established methods [6-18], such as the measurement of dehydrochlorination (DHC) rates and the determination of Congo Red (CR) values. To gain more detailed insight in the chemical behaviour and fate of the polyol additive after dispersion within a PVC matrix and prolonged thermal treatment at $200{ }^{\circ} \mathrm{C}$ [19-32], the polyol and its possible reaction products were extracted from the heattreated unprocessed or ground-processed PVC-polyol mixtures. The product composition of the extracts was established using quantitative ${ }^{13} \mathrm{C}$ NMR spectroscopy.

\section{Experimental}

\subsection{PVC-sample preparation}

All experiments were performed with a standardised pre-mix, a so-called "naked" pipe-formulation, which was kindly supplied by Allstab Chemicals (Table 1).

Polyols were added to the pre-mix and mixed manually. For the sample referred to as unprocessed PVC-sorbitol mixture the amount of sorbitol added was 1.0 part per 100 parts of resin $(1.0 \mathrm{phr})$.

Ground-processed PVC samples were obtained by processing the pre-mix/polyol mixture $(120 \mathrm{~g})$ on a tworoll mill (Schwabenthan Berlin, roll width $22.5 \mathrm{~cm}$, circumference $35 \mathrm{~cm}$, rotation speed front/back: 19/23) at $196{ }^{\circ} \mathrm{C}$ for $2 \mathrm{~min}$, giving a rigid PVC sheet. These sheets were manually cut into small pieces $\left(2 \mathrm{~cm}^{2}\right)$, and subsequently ground (Retsch ultra-centrifugal grinder, ZM 100) under cryogenic conditions, using a $3 \mathrm{~mm}$ sieve. Approximately $66 \%$ of the particles had a particle

Table 1

Composition of the rigid heavy metal- and zinc-free PVC "naked" pipe formulation

\begin{tabular}{lc}
\hline $\begin{array}{l}\text { Pre-mix: rigid PVC } \\
\text { formulation }\end{array}$ & $\begin{array}{l}\text { Parts per hundred } \\
\text { resin (phr) }\end{array}$ \\
\hline S-PVC (Marvylan S6806, ex-LVM) & 100.00 \\
$\mathrm{CaCO}_{3}$ (Omyalite 95T) & 2.00 \\
Paraffin wax (drop point $\left.106-112{ }^{\circ} \mathrm{C}\right)$ & 0.16 \\
Synthetic paraffin (m.p. $\left.73^{\circ} \mathrm{C}\right)$ & 0.46 \\
LDPE wax (drop point $\left.103-110^{\circ} \mathrm{C}\right)$ & 0.10 \\
\hline
\end{tabular}

size smaller than $1.5 \mathrm{~mm}$; they are referred to as groundprocessed PVC-polyol mixtures.

The ground-processed PVC-polyol mixtures either contain various amounts of sorbitol $(0.25,0.50,1.0$ and $1.5 \mathrm{phr}$, respectively) or, instead of sorbitol, other polyols, such as xylitol, erythritol, 1,4-sorbitan, isosorbide, 1,4-galactitan and trimethylolpropane (TMP), respectively) in an amount of $1.0 \mathrm{phr}$.

\subsection{Measurement of the DHC rate}

Unprocessed- $(10.0 \mathrm{~g})$ or ground-processed PVC samples $(5.0 \mathrm{~g})$ were heated at $200{ }^{\circ} \mathrm{C}$ in a DHC set-up that consisted of a reactor (glass reactor, height $160 \mathrm{~mm}$, and diameter $52 \mathrm{~mm}$ ) covered with a removable lid containing an $\mathrm{N}_{2}$ gas inlet (flow rate $20 \mathrm{ml} / \mathrm{min}$ using a Brookfield Sho Rate flow meter) and a curved tube for gas exhaust. Before entering the reactor the $\mathrm{N}_{2}$ gas was first passed through a conc. $\mathrm{NaOH}$ solution to remove $\mathrm{CO}_{2}$ and subsequently through a conc. $\mathrm{H}_{2} \mathrm{SO}_{4}$ solution to remove remaining traces of water. The reactor was immersed in a silicone oil bath (101) with a temperature accuracy $<1{ }^{\circ} \mathrm{C}$. The exhaust gas from the reactor was collected and transferred to the bottom of a titration cell via a small glass tube containing a porous glass diffuser in order to evenly distribute the gas as small bubbles in the titration cell. The titration cell fitted with an $\mathrm{Ag} / \mathrm{AgCl} \mathrm{pH}$-electrode (Metrohm) was filled with an aqueous $\mathrm{NaOH}$ solution ( $\mathrm{pH} 10)$. A $\mathrm{pH}$ of 10 was chosen to ensure rapid extraction of gaseous $\mathrm{HCl}$ from the $\mathrm{N}_{2}$ gas stream into the magnetically stirred solution in the titration cell. The $\mathrm{pH}$ in the titration cell was maintained at $\mathrm{pH} 10$ by automatic titration with a $\mathrm{NaOH}$ solution (Titrisol 0.1 M, Merck) using a 718 STAT TITRINO apparatus (Metrohm). Hence, the amount of consumed $\mathrm{NaOH}$ is directly related to the amount of released $\mathrm{HCl}$ from the sample. Data points were sampled and stored in a PC every $30 \mathrm{~s}$ and include time, $\mathrm{pH}$ and the amount of $\mathrm{NaOH}$ added to the titration cell.

An estimate of the time needed to heat the glass reactor and its contents to $200{ }^{\circ} \mathrm{C}$ was obtained by applying the Fourier method; a time of ca. $2000 \mathrm{~s}$ was found (cf. Appendix), which corresponds to the induction period and the onset of the (near) linear part of the DHC rate curve.

\subsection{Congo Red measurements}

Congo Red (CR) values were determined by transferring ground-processed PVC samples $(6.0 \mathrm{~g})$ to a closed test tube, which was heated to $200{ }^{\circ} \mathrm{C}$ until a strip of CR paper placed at the top of the tube changes colour from blue to red [14]. The time required for the colour change to occur is referred to as the stability time $\left(t_{\mathrm{s}}\right)$. 


\subsection{Extraction procedure}

After heat treatment at $200{ }^{\circ} \mathrm{C}$ for a certain period of time (either in the DHC set-up or in a Werner Mathis oven) the unprocessed as well as ground-processed PVC-polyol mixtures were extracted in order to isolate the polyol and their possible reaction products. The following procedure was used. PVC samples $(5.0 \mathrm{~g})$ were suspended in a mixture of cyclohexanone $(150 \mathrm{ml})$ and water $(80 \mathrm{ml})$. The suspension was intensively stirred for $48 \mathrm{~h}$ at room temperature. The resulting viscous emulsion that contains highly swollen PVC granules was poured on to a sieve and repeatedly washed with cyclohexanone/water (v/v 2:1). The emulsion was subsequently broken by centrifugation (Centaur 2 at $3000 \mathrm{rpm}$ ). The water phase was transferred to a separatory funnel and extensively washed with diethyl ether $(2 \times 100 \mathrm{ml})$. Next, the water layer was separated and concentrated under reduced pressure using a rotary evaporator at $60{ }^{\circ} \mathrm{C}$. The product composition of the remaining solid residue was established using quantitative ${ }^{13} \mathrm{C}$ NMR spectroscopy (Bruker DPX-300 NMR spectrometer operating at $75.5 \mathrm{MHz}$ and $27{ }^{\circ} \mathrm{C}$; solvents $\mathrm{CDCl}_{3}$ and/or DMSO- $d_{6}$ ).

\section{Results and discussion}

\subsection{General}

Although polyols already find application as additives in heavy metal-stabilised PVC compounds [3,4], information about the long-term heat stabilising mechanism of polyols in heavy metal- and zinc-free PVC compounds is limited. Hitherto, two possible mechanisms have been suggested, e.g. (1) the polyol inhibits degradation by substitution of labile chlorines in the PVC polymer backbone or (2) the polyol acts as an $\mathrm{HCl}$ scavenger and therefore suppresses autocatalytic degradation. Since it has been reported that sorbitol does not react with 4-chloro-2-hexene (a PVC model compound) even in the presence of zinc chloride [18,33], a stabilising mechanism by substitution of labile chlorines in the PVC chain is highly unlikely. This is substantiated by the observation that sorbitol exerts a positive effect on the long-term heat stability; it appears to act as an $\mathrm{HCl}$ scavenger. Removal of the released $\mathrm{HCl}$ from the $\mathrm{PVC}$ matrix by sorbitol can be achieved either via coordination/complexation of $\mathrm{HCl}$ by the polyol as found with zinc containing PVC formulations [34] or by a reaction between the polyol and $\mathrm{HCl}$, e.g. substitution of hydroxy groups by chloride ions. It is unlikely, however, that $\mathrm{HCl}$ complexation by metals as previously found with zinc-containing PVC formulations [34] will play a major role, since we apply a heavy metal- and zinc-free PVC pre-mix. Thus, in order to assess which of the two mechanisms contribute in the case of a heavy metal- and zinc-free PVC formulation the effect of various types of (natural) polyols, viz. sorbitol, xylitol, erythritol, 1,4-sorbitan, isosorbide, 1,4-galactitan and trimethylolpropane (TMP), respectively, on the longterm heat stability of PVC has been investigated in both unprocessed and ground-processed PVC-polyol mixtures.

\subsection{Unprocessed PVC-sorbitol mixture}

Firstly, we have studied the effect of sorbitol on the dehydrochlorination (DHC) rate of an unprocessed PVC-sorbitol (1.0 phr) mixture during thermal degradation at $200{ }^{\circ} \mathrm{C}$. As shown by the $\mathrm{DHC}$ rate curves in Fig. 1, neither the induction period (ca. $1000 \mathrm{~s}$ ) nor the DHC rate change when 1.0 phr sorbitol is only manually mixed with the PVC compound (see Section 2.1). This is a significant observation. Note that it has been reported that both the induction period and the DHC rate change when additives capable to react with labile chlorines in the PVC backbone are used. For example, a change of the induction period in combination with a decrease of the DHC rate has been found for 1,3,4-oxadiazole additives, which react with labile chlorines [7] (see also reference [18]). Hence, the lack of any effect for our unprocessed PVC-sorbitol (1.0 phr) mixture hints that sorbitol may indeed act as an $\mathrm{HCl}$ scavenger. This will be substantiated by the results obtained for groundprocessed PVC-sorbitol mixtures (Section 3.3, vide infra).

Extraction of the unprocessed PVC-sorbitol (1.0 phr) mixture (powder) after thermal degradation at $200{ }^{\circ} \mathrm{C}$ for $2.5 \mathrm{~h}$ in the $\mathrm{DHC}$ set up, followed by quantitative ${ }^{13} \mathrm{C} \mathrm{NMR}$ analysis of the extract revealed that besides sorbitol $(86 \%)$ its monoanhydro-derivative 1,4 -sorbitan $(14 \%)$ is also present. This suggests that sorbitol is partly converted to 1,4-sorbitan presumably via an acid-catalysed $(\mathrm{HCl})$ intramolecular cyclodehydration reaction (see also Fig. 4, vide infra) [19-28].

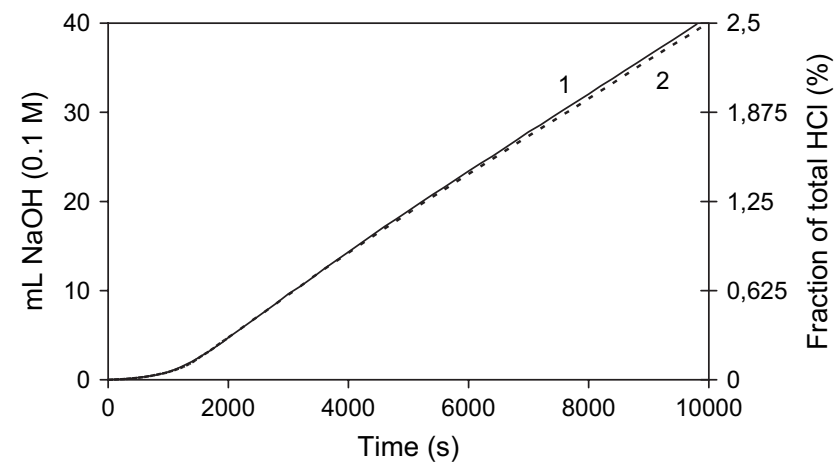

Fig. 1. DHC rates of unprocessed PVC compound in the presence (1; $1.0 \mathrm{phr}$ ) or absence (2) of sorbitol at $200{ }^{\circ} \mathrm{C}$. 


\subsection{Ground-processed PVC-sorbitol mixtures}

Next, the effect of homogeneously dispersed sorbitol in the PVC matrix was studied. This was achieved by processing $\mathrm{PVC}-$ sorbitol mixtures that contain increasing amounts of sorbitol $(0,0.25,0.50,1.0$ and $1.5 \mathrm{phr}$, respectively), on a two-roll mill at $196{ }^{\circ} \mathrm{C}$. The obtained rigid PVC sheets were subsequently ground under cryogenic conditions to particles of size $\leq 3 \mathrm{~mm}$, i.e. the ground-processed PVC-sorbitol mixtures. These samples were subjected to thermal degradation at $200{ }^{\circ} \mathrm{C}$ in the DHC set up (see Fig. 2).

The data show that for the blank (0 phr sorbitol) dehydrochlorination starts at ca. $1000 \mathrm{~s}$. This induction period is in reasonable agreement with a qualitative estimate of the time required to heat the glass reactor and its contents to $200{ }^{\circ} \mathrm{C}$ as determined by the Fourier method (cf. Appendix). After the initial 1000 s the DHC rate for the blank remains nearly constant for the next $5000 \mathrm{~s}$, after which degradation becomes autocatalytic. Although upon addition of increasing amounts of sorbitol the induction period (ca. $1000 \mathrm{~s}$ ) does not change significantly, a substantial decrease of the DHC rate between $1000 \mathrm{~s}$ and $5000 \mathrm{~s}$ is found. Concomitantly, the onset of autocatalytic degradation is delayed; the change being proportional to the amount of sorbitol added. For example, addition of $1.5 \mathrm{phr}$ sorbitol results in a shift of the onset of autocatalytic degradation from $5000 \mathrm{~s}$ (blank) to $10000 \mathrm{~s}$. These observations give credence that in the applied ground-processed heavy metal- and zinc-free PVC formulation sorbitol indeed acts as a $\mathrm{HCl}$ scavenger.

Next, a ground-processed PVC-sorbitol (1.0 phr) mixture was thermally degraded in a Werner Mathis oven $\left(200^{\circ} \mathrm{C}\right)$ from which samples were taken after 1 , $1.5,2.0,2.5$ and $3 \mathrm{~h}$, respectively. Each sample was extracted and the product composition of the extract was determined using quantitative ${ }^{13} \mathrm{C}$ NMR spectroscopy. The results unequivocally show that with increasing time sorbitol is progressively converted into its anhydroderivatives 1,4-sorbitan and finally isosorbide, respectively. As shown by the results in Fig. 3, after $2.5 \mathrm{~h}$,

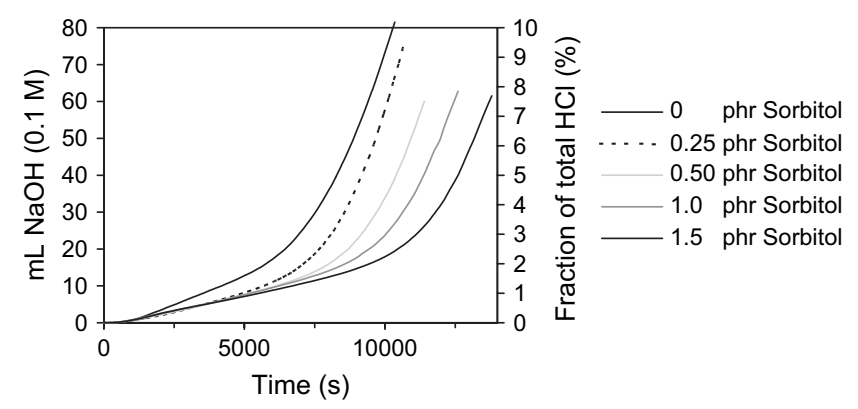

Fig. 2. DHC rates of ground-processed PVC sheets containing various amounts (in phr) of sorbitol at $200{ }^{\circ} \mathrm{C}$. a significant part of the sorbitol is converted into 1,4sorbitan $(25 \%)$ and isosorbide $(15 \%)$. A comparison of the results with those found after extraction of an unprocessed $\mathrm{PVC}$-sorbitol (1.0 phr) mixture that was also thermally degraded for $2.5 \mathrm{~h}$ at $200{ }^{\circ} \mathrm{C}$ (vide supra) reveals that roll-mill processing enhances the conversion of sorbitol into its intramolecular cyclodehydration products (ground-processed $40 \%$ vs. unprocessed 14\%). In combination with the significant reduction of DHC rate this points to a relationship between intramolecular cyclodehydration and the propensity of the added polyol to exert long-term heat stabilisation via $\mathrm{HCl}$ scavenging.

\subsection{The effect of different polyols on DHC rates and $C R$ values}

To gain insight in the effect of intramolecular cyclodehydration of (natural) polyols on their longterm heat stabilising efficacy, different types of polyols (sorbitol, xylitol, erythritol, 1,4-sorbitan, isosorbide, 1,4-galactitan and trimethylolpropane (TMP), respectively) were applied as additives (see Section 2.1). Since the polyols are highly diluted (ca. 1\%) in the groundprocessed PVC-polyol mixtures, we disregard the occurrence of intermolecular dehydration reactions. The applied polyol additives differ in composition (number and type of hydroxyl groups), as well as their propensity to give stable intramolecular cyclodehydration products via 1,4- and 1,5-elimination reactions (Fig. 4). Note that the occurrence of intramolecular cyclodehydration in the case of erythritol, xylitol, and sorbitol, giving 1,4-erythritan, 1,4-xylitan, and 1,4sorbitan and isosorbide (1,4-sorbitan itself may undergo intramolecular cyclodehydration), respectively, at elevated temperatures is documented (Fig. 4) [23-28]. In contrast, 1,4-galactitan does not cyclodehydrate in solution [29]. Note that other possible cyclodehydration reactions, such as 1,2- and 1,3-elimination, will give

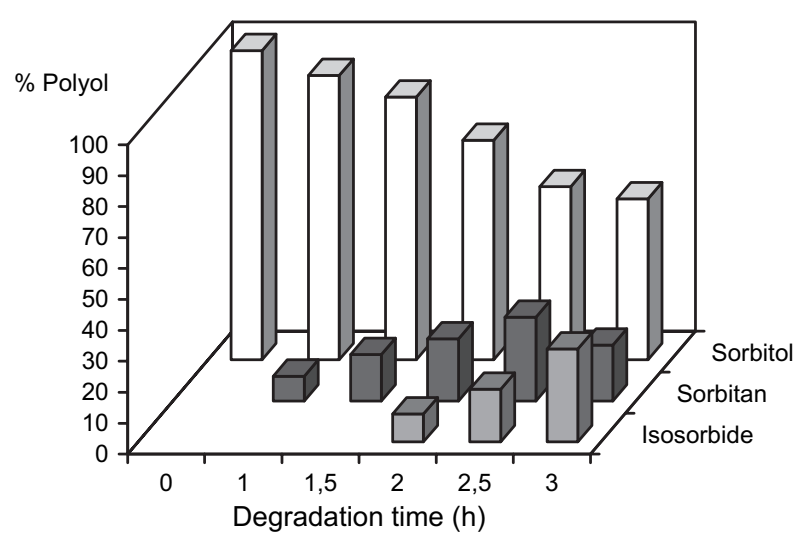

Fig. 3. Extraction results of ground-processed PVC-sorbitol (1.0 phr) mixtures after thermal degradation at $200{ }^{\circ} \mathrm{C}$ vs. time. 


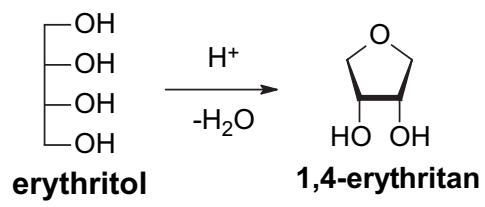

$$
\begin{gathered}
-\mathrm{OH} \\
-\mathrm{OH} \\
-\mathrm{OH} \\
\text { xylitol }
\end{gathered}
$$$$
\underset{-\mathrm{H}_{2} \mathrm{O}}{\stackrel{\mathrm{H}^{+}}{\mathrm{CH}}}
$$<smiles>OCC(O)C(O)C(O)(O)C(O)CO</smiles>

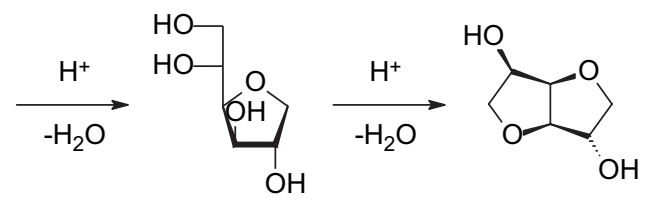
sorbitol

1,4-sorbitan isosorbide

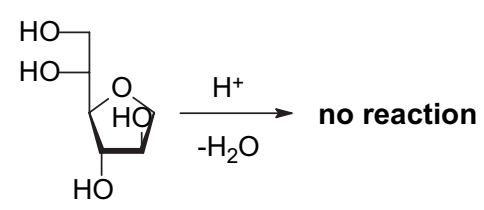

1,4-galactitan

Fig. 4. Natural polyols and their accessible intramolecular cyclodehydration products.

reactive epoxides and oxetanes (e.g. trimethylolpropane (TMP)), respectively, which are expected to readily react with the released $\mathrm{HCl}$ giving ring-opened products containing covalently bound chlorine [30] (Table 2).

The DHC rates and CR values of ground-processed PVC samples containing different types of polyols $(1.0 \mathrm{phr})$ are presented in Figs. 5 and 6, respectively. The results show that the number, type (primary vs. secondary) and the configuration of the hydroxyl groups are important factors for the long-term heat stabilising effect of the polyols.

Isosorbide, the dianhydro-derivative of sorbitol, which only contains secondary hydroxyl groups, exerts little effect on both the $\mathrm{DHC}$ rate and the $\mathrm{CR}$ value when compared to the blank. In contrast, trimethylolpropane (TMP) and 1,4-galactitan, show a significant effect on the long-term heat stability. This suggests that primary hydroxyl groups play an important role for imparting long-term heat stability. According to the measured DHC rates and CR values, both sorbitol and xylitol have the most pronounced effect. It has been established that the intramolecular cyclodehydration of sorbitol to 1,4 -sorbitan is ca. $17 \times$ faster than that of xylitol to 1,4-xylitan [31] and that of sorbitol to 1,4sorbitan is ca. $15 \times$ faster than that of 1,4 -sorbitan to isosorbide [27]. Thus, despite the difference in reactivity of sorbitol and xylitol, only moderate differences are found with respect to their effect on long-term heat stability. The comparable performance of 1,4-sorbitan and 1,4-galactitan indicates that cyclodehydration does not play a major role in the stabilising mechanism (Fig. 5). The only apparent anomaly is erythritol, which according to the DHC rate data is the best performing polyol, while according to its $\mathrm{CR}$ value erythritol only exerts a moderate effect. One should take into account, however, that the DHC rate and CR methods are different procedures (see Section 2). Notwithstanding, they generally provide a qualitatively similar efficacy order for $\mathrm{HCl}$ acid scavenging properties of additives with reasonable reproducibility. Therefore, our longterm thermal stability results in combination with the known reactivity for polyols to undergo intramolecular cyclodehydration leads to the following conclusions: (1) intramolecular cyclodehydration does not contribute to the stabilisation mechanism itself, but represents a competitive reaction that affects the long-term heat stabilising efficacy of the polyol (compare the behaviour of sorbitol, 1,4-sorbitan and isosorbide; see Figs. 4-6). (2) The presence of primary hydroxyl groups is a prerequisite to exert long-term heat stability in our heavy metal- and zinc-free PVC systems. The polyols that enhance long-term heat stability act as $\mathrm{HCl}$ scavengers. (3) The presence of additional neighbouring (secondary) $\beta$-hydroxy groups next to the primary hydroxy groups enhances the propensity of polyols, which further improves long-term heat stability in heavy metal- and

Table 2

\begin{tabular}{|c|c|c|c|c|c|}
\hline Polyols & $\begin{array}{l}\text { Primary } \\
\mathrm{OH}\end{array}$ & $\begin{array}{l}\text { Secondary } \\
\mathrm{OH}\end{array}$ & $\begin{array}{l}\text { Stable intramolecular } \\
\text { cyclodehydration product }\end{array}$ & $M_{\mathrm{W}}$ & $\mathrm{mmol} / \mathrm{phr}$ \\
\hline Trimethylolpropane (TMP) & 3 & - & No & 120 & 10.0 \\
\hline Erythritol & 2 & 2 & Yes; 1,4-erythritan & 122 & 9.8 \\
\hline Xylitol & 2 & 3 & Yes; 1,4-xylitan & 152 & 7.9 \\
\hline Sorbitol & 2 & 4 & Yes; 1,4-sorbitan & 182 & 6.6 \\
\hline 1,4-Sorbitan & 1 & 3 & Yes; isosorbide & 164 & 7.3 \\
\hline 1,4-Galactitan & 1 & 3 & No & 164 & 7.3 \\
\hline Isosorbide & 0 & 2 & No & 146 & 8.2 \\
\hline
\end{tabular}

Properties of the (natural) polyol additives tested in the rigid heavy metal- and zinc-free PVC "naked" pipe PVC formulation (see Table 1 and Fig. 4) 


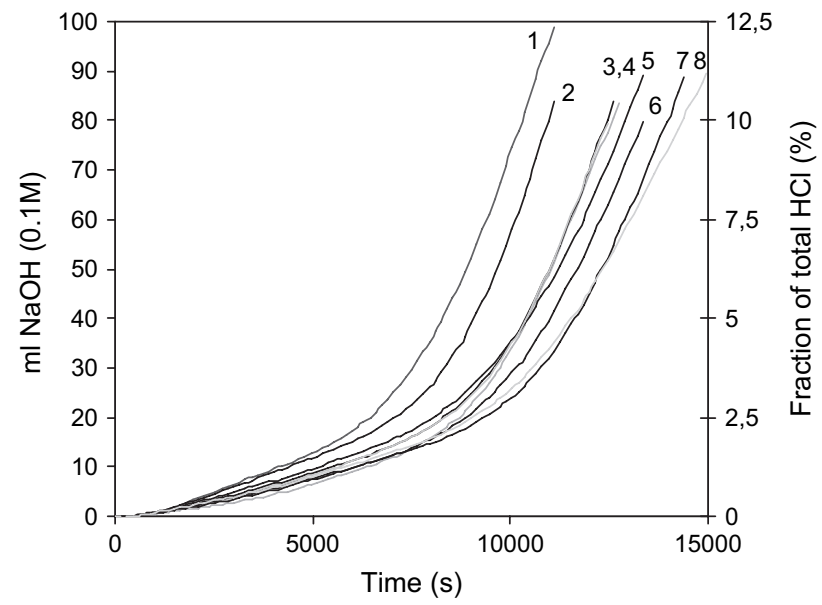

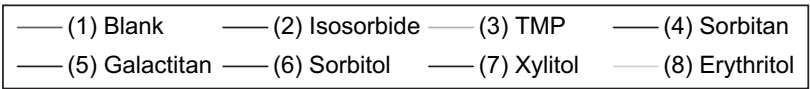

Fig. 5. DHC rates of ground-processed PVC-polyol (1.0 phr) mixtures at $200{ }^{\circ} \mathrm{C}$.

zinc-free PVC systems (compare the behaviour of trimethylolpropane (TMP), 1,4-sorbitan and 1,4-galactitan; see Figs. 4-6).

In line with our results van Tran and Guyot [35] have found a correlation between the number of hydroxyl groups in polyol additives for heavy metal containing PVC and their effect on long-term heat stabilisation. Likewise, Elliott and Hills [36] observed in heavy metal containing PVC that alcohols with only secondary or tertiary hydroxyl groups all represent poor stabilisers. Thus, we conclude that the most viable mechanism is covalent interaction between the released $\mathrm{HCl}$ and the primary hydroxyl moieties of the polyols, e.g. presumably via acid-catalysed substitution of primary hydroxyl group by chloride. Although this possibility has been suggested previously $[35,37,38]$, experimental evidence was hitherto unavailable.

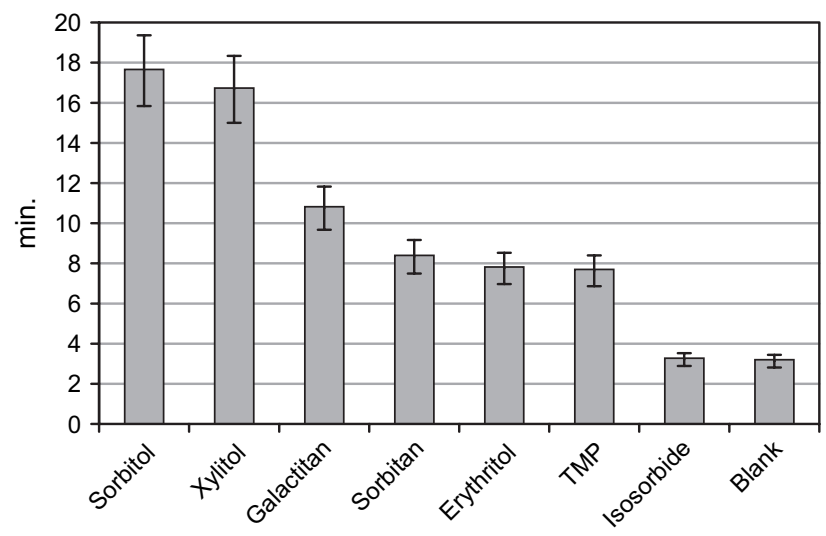

Fig. 6. Congo Red (CR) values of ground-processed PVC-polyol (1.0 phr) mixtures (cf. also Fig. 5).

\section{Conclusions}

A systematic investigation of the effects of natural polyols on the long-term heat stability of a heavy metaland zinc-free rigid PVC formulation has provided new insights. Firstly, according to DHC-rate measurements and the assessment of CR values sorbitol does not react with labile chlorines on the PVC polymer backbone. Instead the polyol exerts long-term heat stabilisation by $\mathrm{HCl}$ scavenging, viz. suppressing/delaying autocatalytic degradation, after homogeneous dispersion of the polyol in the PVC matrix.

The application of (natural) polyols of varying composition as additives and their effect on the longterm heat stability of the corresponding ground-processed PVC-polyol mixtures after prolonged thermal degradation at $200{ }^{\circ} \mathrm{C}$ shows that polyol stabilising efficacy depends on their composition (number and type of hydroxyl groups present). The presence of primary hydroxyl groups is a prerequisite to impart long-term heat stability, which can be further reinforced by the presence of $\beta$-hydroxy groups. Despite the occurrence of competitive intramolecular cyclodehydration reactions, natural polyols like sorbitol and xylitol are effective $\mathrm{HCl}$ scavengers. Hence, it appears that these (natural) polyol additives in heavy metal- and zinc-free PVC scavenge $\mathrm{HCl}$ by substitution of primary hydroxyl groups by chloride ions. The identification of the intermediates that contain covalently bound chlorine is currently under investigations.

Finally, the important aspect of the extent of discolouration, i.e. in particular the effect of (natural) polyol additives on the initial colour of heavy metal- and zinc-free PVC, will be addressed in a subsequent manuscript.

\section{Acknowledgements}

Financial support (J. S.) by the Netherlands Program for Innovation Driven Research (IOP Milieutechnologie/ Zware Metalen) from the Ministry of Economic Affairs and Ministry of Agriculture, Nature Management and Fisheries (IOP project number IZW 98210) is gratefully acknowledged.

\section{Appendix. Estimate of the time involved in raising the temperature of the $\mathrm{PVC}$ batch}

An estimate of the time required to raise the temperature of the PVC in the DHC set up to the temperature of the oil bath was obtained by the following procedure. The bulk volume of ground PVC $(5.00 \mathrm{~g})$ was measured; a volume of $7.1 \mathrm{ml}$ was found, which results in a bulk density of $704 \mathrm{~kg} / \mathrm{m}^{3}$. From the density of PVC $\left(1390 \mathrm{~kg} / \mathrm{m}^{3}\right)$ the porosity of ground 
PVC is determined to be $49 \%$. The radius of the spherical vessel of the DHC set up is $2.9 \mathrm{~cm}$. Fourier's number $\left(F_{0}\right)$, i.e. a measure of the heat conducted through a body relative to the heat stored, is calculated using Eq. (1):

$F_{0}=\frac{\frac{\lambda}{c_{\mathrm{p}} \times \rho} \times t}{L^{2}}$

with $\lambda=0.165 \mathrm{~J} / \mathrm{s} \mathrm{mK}$ (the thermal conductivity of $\mathrm{PVC}$ ), $c_{\mathrm{p}}=2 \times 10^{3} \mathrm{~J} / \mathrm{kg} \mathrm{K}$ (the heat capacity of PVC), $L=0.029 \mathrm{~m}$ (the characteristic length (radius) of the sphere) and $\rho=704 \mathrm{~kg} / \mathrm{m}^{3}$ (bulk density of ground PVC). This leads to the following $F_{0}$ value:

$F_{0}=1.39 \times 10^{-4} \times t$

A difference in mean temperature from the temperature of the oil bath according to Eq. (3)

$\frac{T_{1}-\langle T\rangle}{T_{1}-T_{0}}=10^{-2}$

in which $T_{1}$ is the temperature of the oil bath $\left(200{ }^{\circ} \mathrm{C}\right)$, $T_{0}$ the initial temperature of the PVC powder $\left(20^{\circ} \mathrm{C}\right)$ and $\langle T\rangle$ the mean temperature of the PVC powder. From the Heisler charts [39] a Fourier number of 0.9 is deduced using a difference in mean temperature of $10^{-2}{ }^{\circ} \mathrm{C}$ (Eq. (3)) and an estimated Biot number (Bi) equal to 10.

From Eq. (2) it follows that

$1.39 \times 10^{-4} \times t=0.9$

and

$t=6459 \mathrm{~s}$

Thus, the time to heat the entire sphere is ca. $6500 \mathrm{~s}$. Note, however, that only part of the sphere has to be heated. The layer of ground PVC is at most only $0.8 \mathrm{~cm}$ thick. Therefore, the estimated time to heat this layer is $(0.8 \mathrm{~cm} / 2.9 \mathrm{~cm}) \times 6500 \mathrm{~s}=1800 \mathrm{~s}$, e.g. the time to heat the grounded PVC layer is ca. $2000 \mathrm{~s}$.

\section{References}

[1] Braun D. Poly(vinyl chloride) on the way from the 19th century to the 21st century. J Polym Sci Part A Polym Chem 2004;42: $578-86$.

[2] Vinyl 2010, Progress Report 2004, see also http://www. vinyl2010.org.

[3] Bacaloglu R, Fisch MH, Sander HJ. PVC stabilisers. In: Zweifel $\mathrm{H}$, editor. Plastic additives handbook. Munich: Carl Hanser Verlag; 2000. p. 427-83.

[4] Benavides R, Edge M, Allen NS, Telez MM. Stabilization of poly(vinyl chloride) with preheated metal stearates and costabilizers. II. Use of a polyol. J Appl Polym Sci 1998;68:11-27.
[5] Dworkin RD. PVC stabilizers of the past, present and future. J Vinyl Additive Technol 1989;11:15-22.

[6] Mohamed NA, Sabaa MW. $N$-Acryloyl, $N^{\prime}$-cyanoacetohydrazide as a thermal stabilizer for rigid poly(vinyl chloride). Polym Int 1998:45:147-56.

[7] Mohamed NA, Al-Afaleq EI. Aromatic 1,3,4-oxadiazoles as thermal stabilizers for rigid poly(vinyl chloride). Polymer 1999;40:617-27.

[8] Troitskii BB, Troitskaya LS, Denisova VN, Novikova MA, Luzinova ZB. Investigation of stabilizing effectiveness of alkyl(aryl)tin maleates and thioglycolates in the thermal degradation of poly(vinyl chloride). Eur Polym J 1977;13:1033-41.

[9] Sabaa MW, Mohamed NA, Khalil KD, Yassin AA. Organic thermal stabilizers for rigid poly(vinyl chloride) II. Benzal thiobarbituric acid and some of its derivatives. Polym Degrad Stab 2000;70:121-33.

[10] Minsker KS, Kolesov SV, Yanborisov VM, Zaikov GE. The stabilizing action of $\beta$-dicarbonyl compounds in the thermal decomposition of poly(vinyl chloride). Polym Degrad Stab 1986;15:305-10.

[11] Bensemra N, van Tran H, Michel A, Bartholin M, Guyot A. Thermal dehydrochlorination and stabilization of poly(vinyl chloride) in solution: part III. $\mathrm{Zn}-\mathrm{Ca}$ stearates as stabilizers. Polym Degrad Stab 1989;24:33-50.

[12] Bensemra N, van Tran H, Guyot A, Gay M, Carette L. Thermal dehydrochlorination and stabilization of poly(vinyl chloride) in solution: part IV. Synergistic effects of $\beta$-diketone compounds and metal soap stabilizers. Polym Degrad Stab 1989;24:89-111.

[13] Garrigues C, Guyot A, van Tran H. Thermal dehydrochlorination and stabilization of poly(vinyl chloride) in solution: part XI. Synergism between dialkyltin thioglycolates and organic costabilisers. Polym Degrad Stab 1994;45:103-10.

[14] ISO, Plastics - determination of the tendency of compounds and products based on vinyl chloride homopolymers and copolymers to evolve hydrogen chloride and any other acidic products at elevated temperatures - Part 1: Congo red method, ISO 182-1: 1990(E).

[15] ISO, Plastics - determination of the tendency of compounds and products based on vinyl chloride homopolymers and copolymers to evolve hydrogen chloride and any other acidic products at elevated temperatures - Part 2: pH method, ISO 182-2: 1990(E).

[16] ISO, Plastics - determination of the tendency of compounds and products based on vinyl chloride homopolymers and copolymers to evolve hydrogen chloride and any other acidic products at elevated temperatures - Part 3: Conductometric method, ISO 182-3: 1993(E).

[17] ISO, Plastics - determination of the tendency of compounds and products based on vinyl chloride homopolymers and copolymers to evolve hydrogen chloride and any other acidic products at elevated temperatures - Part 4: Potentiometric method, ISO 182-4: 1993(E).

[18] Onuzaka M, Asahina M. On the dehydrochlorination and the stabilization of polyvinyl chloride. J Macromol Sci-Revs Macromol Chem 1969;C3:253-80.

[19] Wiggins LF. The anhydrides of polyhydric alcohols. Part I. The constitution of isomannide. J Chem Soc 1945;4-5.

[20] Montgomery R, Wiggins LF. The anhydrides of polyhydric alcohols. Part XII. The reaction between mannitol and hydrochloric acid. J Chem Soc 1948;2205-7.

[21] Micheel F. Übergang von der Hexosereihe in die Cyclitreihe. Liebigs Ann Chem 1932;496:77-98.

[22] Wiggins LF. The anhydrides of polyhydric alcohols. Part II. Derivatives of 1,2:5,6-dianhydro mannitol. J Chem Soc 1946; 384-8.

[23] Montgomery R, Wiggins LF. Anhydrides of polyhydric alcohols. Part VI. 1:4-3:6-dianhydro mannitol and 1:4-3:6-dianhydro sorbitol from sucrose. J Chem Soc 1947;433-6. 
[24] Montgomery R, Wiggins LF. The anhydrides of polyhydric alcohols. Part IX. Derivatives of 1,4-anhydrosorbitol from 1,4:3,6-dianhydrosorbitol. J Chem Soc 1948;237-41.

[25] Došen-Micovic L, Čeković Ž. Conformational effects on the mechanism of acid-catalysed dehydration of hexitols. J Phys Org Chem 1998;11:887-94.

[26] Čeković Ž. Stereochemistry of acid catalysed dehydration of hexitol. J Serb Chem Soc 1986;51:205-11.

[27] Bock K, Pedersen C, Thorgersen H. Acid catalysed dehydration of alditols. Part I. D-glucitol and D-mannitol. Acta Chem Scand 1981;4:441-9.

[28] Montgomery R, Wiggins LF. The anhydrides of polyhydric alcohols. Part IV. The constitution of dianhydro sorbitol. J Chem Soc 1946;390-2.

[29] (a) Duclos A, Fayet C, Gelas J. A simple conversion of polyols into anhydroalditols. Synthesis 1994;1087-90;

(b) Kurszewska M, Skorupa E, Kasprzykowska R, Sowinski P, Wisniewski A. The solvent-free thermal dehydration of tetritols on zeolites. Carbohydr Res 2000;326:241-9.

[30] (a) Jarman M, Stevens JD, Horvath IP, Hegedues L. 1,2Anhydro-6-chloro-6-deoxy-D-mannitol and 1,2-anhydro-6-chloro6-deoxygalactitol. Carbohydr Res 1979;72:309-11;

(b) Vidra I, Institoris L, Simon K, Czugler M, Csoeregh I. 1,5-Dihalogeno- and 1,2:4,5-dianhydroxylitol derivatives. Part I. Synthesis and structure of 1,5-dideoxy-1,5-dihalogeno- and 1,2:4,5-dianhydroxylitol derivatives. Carbohydr Res 1983;111: 215-23.

[31] Barker R. Conversion of acyclic carbohydrates into tetrahydrofuran derivatives. Acid-catalysed dehydration of hexitols. J Org Chem 1970;35:461-4.
[32] Thalmaier M, Braun D. Zum Mechanismus der thermischen Chlorwasserstoff-abspaltung aus Polyvinylchlorid. 4. Mitt. Über die Länge de Polysequenzen in partiell dehydrochloriertem Polyvinylchlorid. Makromol Chem 1967;108:241-54.

[33] van Tran H, Michel A, Guyot A. Chloride formation and polymer coloration during thermal degradation of PVC stabilised with a $\mathrm{Zn-Ca}$ recipe. Polym Degrad Stab 1979;1:237-48.

[34] (a) Guyot A, Michel A. Stabilisation of polyvinyl chloride with metal soaps and organic compounds. Developments in polymer stabilization 1980;2:89-124;

(b) Briggs G, Wood NF. An investigation of mechanisms of synergistic interactions in PVC stabilization. J Appl Polym Sci 1971;15:25-37;

(c) Iida T, Goto K. Stabilization of poly(vinyl chloride). V. Synergism between metal soaps and polyols upon stabilization of poly(vinyl chloride). J Appl Polym Sci 1980;25:887-900.

[35] van Tran H, Guyot A. The role of polyols as secondary stabilisers for poly(vinyl chlorides). Polym Degrad Stab 1985;12:29-41.

[36] Elliott SB, Hills W. Vinyl chloride resin stabilised with polyhydric alcohols and Friedel-Crafts catalyst, Patent assigned to: Ferro Chemical Corporation, US 2,861,052; 1958.

[37] Abbas KB, Sörvik EM. Heat stabilizers for poly(vinyl chloride) I. Synergistic systems based on calcium/zinc stearate. J Vinyl Additive Technol 1980;2:87-94.

[38] Grossman RF, Krausnick D. Heat stabilizers for halogenated polymers. In: Lutz JT, Grossman RF, editors. Polymer modifiers and additives. New York: Marcel Dekker Inc.; 2000. p. $273-312$.

[39] Incorpa FP, De Witt DP. Introduction to heat transfer. New York: Wiley \& Sons; 1990. 